23 Nopember 2015

12:07

Wesi Page 1 


\title{
HUBUNGAN PERILAKU ORANG TUA DALAM PENGAMBILAN KEPUTUSAN DENGAN DERAJAT DENGUE HEMORRHAGIC FEVER PADA ANAK DI RUMAH SAKIT BHAKTI RAHAYU SURABAYA Amiriah Arminah *, Wesiana Heris Santy**
}

\begin{abstract}
The decision making which is not done promptly and correctly can result in death because the incidence rate of DHF increases 5\% each year. The purpose of this study was to study the correlation between the parents' behavior in making decision and the severity level of DHF in children at RS BRS. The method was analytical done by using a retrospective approach. The population involved all parents whose children suffering from DHF at RS BRS, totally 30 respondents in which 28 respondents were taken as the samples by using simple random sampling technique. The independent variable was the the parents' behavior in making decision, whereas the dependent variable was the severity level of DHF. The data were taken by using questionnaires and analyzed by uisng Mann-Whitney test in which $\alpha=0.05$. The results showed that among 13 respondents who have made decisions promptly, almost entirely $(84.6 \%)$ had DHF at level $\quad 1$. While $15 \quad$ respondents who took the decision late, nearly all (40\%) had DHF at level 2 . After Mann-Whitney test, the research obtained $\rho=0.005$ and $=0.05$, meaning that $\rho<\alpha$, so that $\mathrm{H}_{0}$ was rejected, showing that there was a correlation between the parents' behavior and decision-making with the severity level of DHF at RSBRS. It concluded that the late decisionmaking resulting in the increase of severity level of DHF. Therefore, the parents are expected to make decisions quickly when the children has a fever to medically detect the disease immediately and the children immediately receive the appropriate actions .
\end{abstract}

\footnotetext{
Abstrak : Pengambilan keputusan yang dilakukan secara tidak cepat dan tepat dapat mengakibatkan pada kematian. Hal ini dikarenakan perjalanan penyakit DHF yang sangat cepat dimana angka kematian DHF mencapai 5\% setiap tahunnya (WHO 2004). Tujuan penelitian untuk mengetahui hubungan perilaku orang tua dalam pengambilan keputusan dengan derajat DHF pada anak di RSBRS. Metode penelitian bersifat analitik dengan pendekatan retrospektif. Populasi adalah semua orang tua yang anaknya menderita DHF sebesar 30 responden dan besar sampel 28 responden. Pengambilan sampel menggunakan cara simple random sampling. Variabel bebas yaitu perilaku orang tua dalam pengambilan keputusan. Variabel terikat yaitu derajat DHF. Data diambil dengan kuesioner dan dianalisis dengan uji Mann-Whitney dimana $\alpha=0,05$. Hasil penelitian menunjukkan 13 responden yang mengambil keputusan secara cepat, hampir seluruhnya $(84,6 \%)$ menderita DHF pada derajat 1 . Sedangkan 15 reponden yang mengambil keputusan secara lambat, hampir seluruhnya (40\%) menderita DHF pada derajat 2. Setelah dilakukan uji Mann-Whitney, diperoleh nilai $\rho=0,005$ dan $\alpha=0,05$, berarti $\rho<\alpha$, maka $\mathrm{H}_{0}$ ditolak artinya ada hubungan perilaku orang tua dalam pengambilan keputusan dengan derajat DHF di RSBRS.Kesimpulan bahwa pengambilan keputusan yang lambat mengakibatkan derajat DHF meningkat. Diharapkan orang tua dapat mengambil keputusan secara cepat saat anak menderita deman agar penyakit segera diketahui secara medis dan anak segera mendapatkan tindakan yang sesuai.

Kata kunci : pengambilan keputusan, derajat DHF
} 


\section{PENDAHULUAN}

Berat ringannya penyakit Dengue Hemorrhagic Fever (DHF) dipengaruhi oleh lingkungan, perilaku (pengambilan keputusan), genetik, dan pelayanan kesehatan (Mubarok, 2009). Pengambilan keputusan merupakan salah satu contoh bentuk dari perilaku. Pengambilan keputusan yang dilakukan secara tidak cepat dan tepat dapat mengakibatkan pada kematian. Hal ini dikarenakan perjalanan penyakit DHF yang sangat cepat. Dengan keputusan yang diambil secara cepat maka DHF dapat segera ditangani sehingga mengurangi terjadinya manifestasi DHF yaitu Dengue Shock Syndrome (DSS) dan kematian (Widoyono, 2008).

\begin{tabular}{|c|c|c|}
\hline \multirow{2}{*}{ Tahun } & \multicolumn{2}{|c|}{ Jawa Timur } \\
\cline { 2 - 3 } & Penderita & Meninggal \\
\hline 2008 & 16.929 & 166 \\
\hline 2009 & 19.175 & 183 \\
\hline
\end{tabular}

Tabel 1.1 Jumlah Kejadian DHF di Jawa Timur pada tahun 2008-2009 dan Kelas 2, 3 Rumah Sakit Bhakti Rahayu Surabaya pada tahun 2010-2011

Faktor yang mempengaruhi pengambilan keputusan yaitu pendidikan, pengalaman, nilai agama, dan adat istiadat. Pengambilan keputusan yang terlambat pada penderita DHF dapat mengakibatkan penyakit-penyakit lain seperti, kerusakan liver, kerusakan otak dan yang paling parah yaitu dapat terjadi Dengue Shock Syndrome (DSS).

Untuk meminimalkan angka kematian penderita DHF yang disebabkan karena pengambilan keputusan, maka masyarakat khususnya orang tua jika anaknya panas maka segera untuk dibawa ke pelayanan kesehatan agar diketahui segera penyakit yang diderita anak. Selain itu, sebaiknya pemerintah juga memberikan pengetahuan kepada orang tua tentang DHF dan pengambilan keputusan untuk segera membawa anaknya ke pelayanan kesehatan jika anak mengalami demam lebih dari 3 hari.

Berdasarkan latar belakang di atas maka peneliti tertarik untuk menganalisa Adakah hubungan antara perilaku orang tua dalam pengambilan keputusan dengan derajat Dengue Hemorrhagic Fever (DHF) pada anak di Rumah Sakit Bhakti Rahayu Surabaya?

\section{METODE PENELITIAN}

Jenis dan Rancang Bangun Penelitian Desain penelitian yang digunakan

Tathainm penelíkiahs zidfan adalah jenis penelitinmah Sakid dikakti Radedangkan pendekatan yasgrablagunakan secara

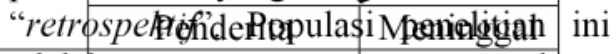
2adalah 30 s\$ng tua yang anaknya 29mqnderita D\&bfo di Rumah Sakit Bhakti Rahayu Surabaya. Sampel dalam penelitian ini adalah sebagian orang tua yang anaknya menderita DHF di Rumah Sakit Bhakti Rahayu Surabaya. Besar sampel yang digunakan dalam penelitian ini sebanyak 28 orang tua yang anaknya menderita DHF di Rumah Sakit Bhakti Rahayu Surabaya. Tehnik sampling proses menyeleksi porsi dari populasi untuk dapat mewakili populasi. Pada penelitian ini sampling adalah dilakukan secara "probability sampling", Teknik yang digunakan adalah "simple random sampling". Variabel penelitian sebagai berikut Variabel Independen : Perilaku orang tua dalam pengambilan keputusan dikategorikan perilaku cepat dan perilaku lambat. Variabel Dependen : Derajat DHF di kategorikan menjadi 
DHF derajar 1,derajat 2, derajat 3 dan derajat 4. Hasil kuesioner yang terkumpul, data dalam skala nominal-

\section{HASIL PENELITIAN PEMBAHASAN}

DAN

a. Hasil

\section{Data Umum}

Pendidikan

Tabel 1 Distribusi frekuensi responden menurut pendidikan orang tua yang anaknya menderita DHF di Rumah Sakit Bhakti Rahayu Surabaya 2012

\begin{tabular}{llll}
\hline No & Tingkat & Frekuensi & Persentase \\
& Pendidikan & & \\
\hline 1 & Dasar & 5 & $17,9 \%$ \\
2 & Menengah & 20 & $71,4 \%$ \\
3 & Tinggi & 3 & $10,7 \%$ \\
\hline & Jumlah & 28 & $100 \%$ \\
\hline
\end{tabular}

Berdasar tabel 1 didapat hasil penelitian bahwa dari 28 responden, sebagian besar $(71,4 \%$ atau 20 orang) responden berpendidikan menengah.

\section{Data Khusus}

\section{Pengambilan Keputusan}

Tabel 2 Distribusi frekuensi responden pengambilan keputusan yang dilakukan oleh orang tua yang anaknya menderita DHF di Rumah Sakit Bhakti Rahayu Surabaya 2012

\begin{tabular}{llll}
\hline No & $\begin{array}{l}\text { Pengambilan } \\
\text { Keputusan }\end{array}$ & Frekuensi & Persentase \\
\hline 1 & Cepat & 13 & $46,4 \%$ \\
2 & Lambat & 15 & $53,6 \%$ \\
\hline & Jumlah & 28 & $100 \%$ \\
\hline
\end{tabular}

Berdasarkan Tabel 2 dapat dilihat dari 28 orang responden, sebagian besar $(53,6 \%$ atau 15 orang) responden mengambil keputusan secara lambat.

\section{Derajat DHF}

Tabel 3 Distribusi frekuensi responden menurut derajat DHF anak di Rumah Sakit Bhakti Rahayu Surabaya

\begin{tabular}{clll}
\hline No & Derajat DHF & Frekuensi & Persentase \\
\hline 1 & 1 (Ringan) & 16 & $57,1 \%$ \\
2 & 2 (Sedang) & 8 & $28,6 \%$
\end{tabular}

ordinal diproses dan dianalisa menggunakan uji Mean-Whitney dengan SPSS pada tingkat kemaknaan $\alpha=0,05$

\begin{tabular}{llll}
\hline 3 & 3 (Berat) & 4 & $14,3 \%$ \\
4 & 4 (Berat & 0 & $0 \%$ \\
& Sekali) & & \\
\hline & Jumlah & 28 & $100 \%$ \\
\hline
\end{tabular}

Tabel 3 menunjukkan bahwa sebagian besar $(57,1 \%$ atau 16 anak) responden mengalami DHF pada derajat 1 (ringan).

\section{Tabulasi silang antara perilaku orang tua dalam pengambilan keputusan dengan derajat DHF pada anak}

Tabel 4 Tabulasi silang hubungan perilaku orang tua dalam pengambilan keputusan dengan derajat DHF pada anak di Rumah Sakit Bhakti Rahayu Surabaya 2012

\begin{tabular}{|c|c|c|c|c|c|c|c|}
\hline \multirow{3}{*}{$\begin{array}{l}\text { Perilaku } \\
\text { orang tua } \\
\text { dalam } \\
\text { pengambila } \\
\text { nkeputusan }\end{array}$} & \multicolumn{5}{|c|}{ Derajat DHF } & \multicolumn{2}{|c|}{ Jumlah } \\
\hline & $\begin{array}{l}\text { T } \\
\text { (Ringan) }\end{array}$ & $\begin{array}{l}2 \\
\text { (Sedang) }\end{array}$ & $\begin{array}{l}3 \\
\text { (Berat) }\end{array}$ & 4 & & & \\
\hline & $\%$ & $\mathrm{n} \%$ & $\mathrm{n} \%$ & $\bar{n}$ & $\%$ & $\mathrm{n}$ & $\%$ \\
\hline Capat & 84,6 & $\begin{array}{ll}2 & 15,4\end{array}$ & 00 & 7 & 0 & 13 & 100 \\
\hline Lambat & $5 \quad 33,3$ & 640 & $4 \quad 26,7$ & 7 & 0 & 15 & 100 \\
\hline Jumlah & $\begin{array}{ll}16 & 57,2\end{array}$ & $8 \quad 28,6$ & $4 \quad 14,2$ & 7 & 0 & 28 & 100 \\
\hline
\end{tabular}

Dari tabel 5.4 di atas dari 28 responden diperoleh 13 responden yang mengambil keputusan secara cepat, hampir seluruh $(84,6 \%$ atau 11 anak) menderita DHF pada derajat 1 (ringan), sedangkan 15 responden yang mengambil keputusan secara lambat, hampir setengah $(40 \%$ atau 4 anak) menderita DHF pada derajat 2 (sedang).

Setelah dilakukan perhitungan melalui Mann-Whitney $U$, didapatkan nilai $\rho=$ 0,005 dan $\alpha=0,05$, berarti $\rho<\alpha(0,005$ $<0,05)$ maka $\mathrm{H}_{0}$ ditolak dimana terdapat hubungan perilaku orang tua dalam pengambilan keputusan dengan 
derajat DHF pada anak di Rumah Sakit Bhakti Rahayu Surabaya.

\section{b. Pembahasan}

Perilaku orang tua dalam pengambilan keputusan yang anaknya menderita DHF

Hasil penelitian menunjukkan bahwa dari 28 responden, orang tua yang anaknya menderita DHF sebagian besar $(53,6 \%)$ mengambil keputusan secara lambat untuk membawa anaknya ke Rumah Sakit Bhakti Rahayu Surabaya.

Pengambilan keputusan merupakan suatu rangkaian tahapan yang dianalisis, diperlukan, dipadukan, dan pada akhirnya dihasilkanlah ketepatan serta ketelitian dalam menyelesaikan masalah (Suarli, 2010). Berdasar hasil kuisioner $46.4 \%$ responden membawa anaknya ke RS setelah lebih dari 2 hari demam, $82.1 \%$ dilakukan kompres dingin, 35.8 $\%$ tidak membawa ke tempat kesehatan sebelumnya. Dari pengertian dan hasil tersebut, dapat disimpulkan bahwa responden terlambat dalam mengambil keputusan sebaiknya pada saat anak demam dilakukan tindakan penannganan secara cepat apalagi jika ternyata lingkungan sekitar ada yang menderita DHF.

Menurut Gemilang (2011), ada empat aktivitas dalam proses pengambilan keputusan yaitu intelligence (pengumpulan informasi untuk mengidentifikasi masalah), design (tahap perancangan solusi dalam bentuk alternatif-alternatif pemecahan masalah), choice (tahap memilih solusi dari alternatif-alternatif yang disediakan), dan implementation (tahap melaksanakan keputusan dan melaporkan hasilnya). Dari hasil kuesioner didapatkan sebagian besar $(56,4 \%)$ orang tua tidak membawa anaknya ke Rumah Sakit Bhakti Rahayu
Surabaya pada saat anak menderita panas tinggi pada hari pertama atau kedua, maka peneliti berpendapat bahwa 4 aktivitas menurut teori gemilang (2011) sebaiknya dilakukan secara cepat dan tepat, karena keputusan yang diambil secara cepat tapi tidak tepat atau secara tepat tapi tidak cepat akan membuahkan hasil yang sia-sia karena mengingat perjalanan penyakit DHF yang cepat dan membutuhkan tindakan yang benar agar anak tidak sakit lagi.

Penelitian ini menunjukkan bahwa sebagian besar $(71,5 \%)$ responden berpendidikan menengah. Dalam teori Purba (2009), faktor-faktor yang mempengaruhi pengambilan keputusan yaitu pendidikan, pengalaman, nilai agama, dan adat istiadat. Sedangkan, dari hasil penelitian menunjukkan bahwa pendidikan tidak mempengaruhi pengambilan keputusan. Hal ini dikarenakan ada beberapa responden yang berpendidikan menengah tapi keputusan diambil secara lambat, sedangkan responden yang berpendidikan dasar ada yang mengambil keputusan secara cepat. Maka dapat disimpulkan bahwa pendidikan bukanlah satu-satunya yang dapat mempengaruhi pengambilan keputusan, ada faktor lain yang mempengaruhi pengambilan keputusan. Seperti yang telah diungkapkan Purba (2009) bahwa pengalaman, nilai agama, dan adat istiadat juga dapat mempengaruhi seseorang untuk mengambil sebuah keputusan.

Derajat Dengue Hemorrhagic Fever (DHF) pada anak Penelitian ini menunjukkan bahwa sebagian besar $(57,1 \%)$ mengalami DHF pada derajat satu (ringan). Diagnosa DHF dapat diketahui dari tanda dan gejalanya. Menurut Soegijanto (2003), gejala 
klinik utama pada DHF adalah demam tinggi mendadak, manifestasi baik yang timbul secara spontan maupun uji tourniquet, trombositopenia, hemokonsentrasi. Sesuai dengan teori, peneliti melihat gejala-gejala responden pada hari pertama masuk seperti panas tinggi dan adanya bintik merah pada tubuh anak. Dan dari hasil laboratorium anak didapatkan adanya trombositopenia, dan hemokonsentrasi. Selain itu diagnosa dokter juga menyatakan bahwa anak menderita DHF.

Dalam teori Blum (Mubarok, 2009) digambarkan bahwa salah satu faktor yang mempengaruhi derajat kesehatan yaitu lingkungan. Dari hasil wawancara, peneliti menyimpulkan bahwa lingkungan responden bisa dikatakan tidak bersih karena penderita yang mengalami DHF pada derajat sedang maupun berat sering menggantungkan pakaiannya didalam kamar dalam jumlah banyak. Kebiasaan tersebut memberikan kesempatan nyamuk Ae.aegypti untuk berkembang biak secara sempurna.

Dalam teori WHO (2007), penyakit DHF dapat mengakibatkan penyakitpenyakit lain jika tidak segera ditangani atau diobati. Penyakit-penyakit tersebut antara lain encephalophaty, kerusakan liver, kerusakan otak dan kejang. Selain itu, komplikasi yang berat dan dapat mengakibatkan kematian yaitu Dengue Shock Syndrome (DSS). Dari hasil wawancara, beberapa orang tua yang anaknya menderita DHF pada derajat sedang maupun berat mengaku bahwa awalnya anak hanya menderita panas tinggi saja tapi setelah keesokan atau dua harinya lagi terdapat bintik merah ditubuh anak, bahkan ada juga yang ujung-ujung jarinya dingin dan ada juga yang mengalami perdarahan di hidung.

\section{Hubungan perilaku orang tua dalam pengambilan keputusan dengan derajat DHF pada anak}

Hasil penelitian menunjukkan bahwa dari 28 responden diperoleh 13 responden yang mengambil keputusan secara cepat, hampir seluruh $(84,6 \%)$ menderita DHF pada derajat satu (ringan), sedangkan 15 responden yang mengambil keputusan secara lambat, hampir setengah sebanyak $(40 \%)$ menderita DHF pada derajat dua (sedang).

Setelah dilakukan uji Mann-Whitney $U$ maka diperoleh nilai $\rho=0,005$ dan $\alpha$ $=0,05$, berarti $\rho<\alpha(0,005<0,05)$, maka $\mathrm{H}_{0}$ ditolak berarti terdapat hubungan perilaku orang tua dalam pengambilan keputusan dengan derajat DHF pada anak di Rumah Sakit Bhakti Rahayu Surabaya.

Menurut Notoatmodjo (2007), perilaku dapat dibedakan menjadi dua yaitu perilaku tertutup (covert behavior) dan perilaku terbuka (overt behavior). Perilaku tertutup dapat diketahui melalui wawancara atau focus group discussion (FGD), sedangkan untuk perilaku terbuka dapat diketahui melalui observasi langsung atau wawancara dengan pendekatan recall atau mengingat kembali. Untuk mengetahui penyebab tingginya derajat DHF dapat ditanyakan apakah orang tua segera membawa ke pelayanan kesehatan terdekat ketika anaknya demam tinggi dua hari. Dimana tindakan orang tua membawa anak ke pelayanan kesehatan merupakan salah satu contoh pengambilan keputusan. Hal ini dibuktikan oleh hasil kuesioner, dimana hampir setengahnya $(35,8 \%)$ orang tua tidak segera membawa anaknya ke pelayanan kesehatan terdekat sehingga setengahnya $(50 \%)$ anak menderita 
DHF pada derajat dua (sedang) dan tiga (berat).

Selain membawa ke pelayanan kesehatan, pemberian kompres juga merupakan contoh pengambilan keputusan yang dapat dilakukan oleh orang tua agar DHF tidak semakin parah. Menurut Febri (2012), salah satu cara untuk menurunkan panas terutama pada penderita DHF agar tidak menjadi parah yaitu dengan mengompres bagian tubuh anak yang mempunyai pembuluh darah besar (seperti leher, ketiak, lipatan paha/selangkangan) dan juga bagian luar yang terbuka (seperti dahi dan perut) dengan air hangat. Kompres hangat membuat pembuluh darah tepi di kulit melebar yang selanjutnya membuat pori-pori terbuka sehingga memudahkan pengeluaran panas dari tubuh. Hal ini terbukti bahwa hampir seluruhnya $(82,1 \%)$ orang tua memberikan kompres dingin saat anak mengalami panas, karena hampir seluruhnya orang tua menganggap dengan memberikan kompres dingin akan membuat tubuh anak dingin. Selain bahan yang digunakan untuk mengompres tidak sesuai dengan teori. Cara responden untuk mengompres pun tidak sesuai, responden hanya meletakkan air dingin (alat kompres) pada kening saja. Padahal cara yang benar adalah meletakkan air pada leher, ketiak, lipatan paha/ selangkangan, dahi dan perut). Perilaku tersebut membuktikan bahwa pengetahuan responden masih sangat kurang karena dengan memberikan kompres dingin, pembuluh darah tepi mengecil sehingga panas yang seharusnya dialirkan darah ke kulit agar keluar tubuh menjadi terhalang sehingga panas tubuh tidak berkurang. Sebaiknya berilah kompres hangat saat anak menderita demam agar pembuluh darah melebar dan mempermudahkan panas keluar dari tubuh.

Dari pernyataan ketiga pada lembar kuesioner didapatkan hampir seluruhnya $(96,4 \%)$ orang tua memberikan obat penurun panas saat anak menderita panas. Yang dilakukan oleh responden sudah benar, karena selain memberikan kompres hangat, panas juga dapat diturunkan dengan memberi anak obat penurun panas (seperti paracetamol, ibuprofen), baik dalam bentuk sirup maupun tablet. Selain dapat menurunkan panas, obat penurun panas juga bisa mengurangi rasa sakit, pegal, dan sakit kepala yang jika dibiarkan menyebabkan derajat DHF meningkat. Rasa sakit, pegal dan sakit kepala juga dirasakan oleh penderita DHF. Hal ini didukung oleh teori Soegijanto (2003), gejala klinik pada penderita DHF yaitu lemah, mual, muntah, sakit perut, diare dan sakit kepala.

\section{SIMPULAN DAN SARAN}

Setelah dilakukan penelitian pada orang tua yang anaknya menderita DHF di Rumah Sakit Bhakti Rahayu Surabaya, maka dapat disimpulkan bahwa :

1. Orang tua yang anaknya menderita DHF sebagian besar mengambil keputusan secara lambat untuk membawa anaknya ke Rumah Sakit Bhakti Rahayu Surabaya.

2. Anak yang menderita DHF di Rumah Sakit Bhakti Rahayu Surabaya sebagian besar mengalami DHF pada derajat 1 (ringan).

3. Ada hubungan perilaku orang tua dalam pengambilan keputusan dengan derajat DHF pada anak di Rumah Sakit Bhakti Rahayu Surabaya. 


\section{DAFTAR PUSTAKA}

Arikunto. 2006. Prosedur Penelitian Suatu Pendekatan, Jakarta : Rineka Cipta

Decha. 2012. Pasien Demam Jangan Diselimuti.

http://www.dechacare.com. diakses tanggal 20 Februari 2012.

Dinkes Jatim 2009. Profil Kesehatan Propinsi Jawa Timur 2009. http://dinkes .jatimprov.go.id. Diakses tanggal 18 Oktober 2011.

Effendy, Nasrul. 2009. Dasar-Dasar Keperawatan Kesehatan Masyarakat. Jakarta : EGC

Effendy, Nasrul. 2004. Dasar-Dasar Keperawatan Masyarakat. Jakarta : EGC

Febri. 2012. Mengatasi Demam Pada Anak. http://www.gagasmedia.net. Diakses tanggal 20 Februari 2012.

Gemilang, Route. 2011. Pengambilan Keputusan.

http://routeterrjtory.files. Diakses tanggal 20 Februari 2012. Pukul 18.00

Hadinegoro, S. 2001. Tatalaksana Demam Berdarah Dengue di Indonesia. Jakarta : Depkes RI

Mobarok, Wahid. 2009. Ilmu Kesehatan Masyarakat: Teori dan Aplikasi. Jakarta : Salemba Medika

Notoatmodjo, Soekidjo. 2007. Promosi Kesehatan dan Ilmu Perilaku. Jakarta : Rineka Cipta.

Pieter, Herri Zan. 2010. Pengantar Psikologi dalam Keperawatan. Jakarta : Kencana
Purba, Marlinda. 2009. Dilema Etik dan Pengambilan Keputusan Etis Dalam Praktik Keperawatan Jiwa. Jakarta : EGC

Setiadi. 2007. Konsep dan Penulisan Riset Keperawatan, Yogyakarta : Graha Ilmu.

Soegijanto. 2003. Demam Berdarah Dengue : Tinjauan dan Temuan Baru di Era 2003. Surabaya : Airlangga University Press.

Undang-Undang Kesehatan. 2004. Arkola : Surabaya

Wasis. 2008. Pedoman Riset Praktis Untuk Profesi Perawat, Jakarta : EGC.

Widiyanto, Teguh. 2007. Tesis Kajian Manajemen Lingkungan terhadap Kejadian Demam Berdarah Dengue (DBD) di Purwokerto Jawa Tengah. Semarang : Universitas Diponegoro Semarang.

Widoyono. 2008. Penyakit Tropis Epidemiologis, Penularan, Pencegahan dan Pemberantasan. Semarang : Erlangga.

World Health Organization. 2004. Panduan Lengkap Pencegahan dan Pengendalian Dengue dan Demam Berdarah Dengue. Jakarta : EGC

World Health Organization. 2007. Demam Berdarah Dengue. Jakarta : EGC 